\title{
Article \\ Do Gas Nanobubbles Enhance Aqueous Photocatalysis? Experiment and Analysis of Mechanism
}

\author{
Weijia Yu ${ }^{1,+} \mathbb{D}$, Jiaying Chen ${ }^{1,+}$, Mohamed Ateia ${ }^{2,3, *(\mathbb{D} \text {, Ezra L. Cates }}{ }^{3}$ and Matthew S. Johnson ${ }^{1, *(\mathbb{D})}$ \\ 1 Department of Chemistry, Faculty of Science, Universitetsparken 5, University of Copenhagen, \\ DK-2100 Copenhagen, Denmark; weijia@chem.ku.dk (W.Y.); qkn963@alumni.ku.dk (J.C.) \\ 2 Department of Chemistry, Northwestern University, 2145 Sheridan Road, Evanston, IL 60208, USA \\ 3 Department of Environmental Engineering and Earth Sciences, Clemson University, Clemson, SC 29634, USA; \\ ecates@clemson.edu \\ * Correspondence: ateia@northwestern.edu (M.A.); msj@chem.ku.dk (M.S.J.); Tel.: +45-35320300 (M.S.J.) \\ + These authors contribute equally to this work.
}

Citation: Yu, W.; Chen, J.; Ateia, M.; Cates, E.L.; Johnson, M.S. Do Gas

Nanobubbles Enhance Aqueous Photocatalysis? Experiment and Analysis of Mechanism. Catalysts 2021, 11, 511. https://doi.org/ $10.3390 /$ catal11040511

Academic Editors: Gassan Hodaifa and Ewa Kowalska

Received: 19 March 2021

Accepted: 17 April 2021

Published: 19 April 2021

Publisher's Note: MDPI stays neutral with regard to jurisdictional claims in published maps and institutional affiliations.

Copyright: (c) 2021 by the authors. Licensee MDPI, Basel, Switzerland. This article is an open access article distributed under the terms and conditions of the Creative Commons Attribution (CC BY) license (https:/ / creativecommons.org/licenses/by/ $4.0 /)$.

\begin{abstract}
The performance of photocatalytic advanced oxidation must be improved in order for the technology to make the jump from academic research to widespread use. Research is needed on the factors that cause photocatalysis to become self-limiting. In this study, we introduced, for the first time, nanobubbles continuously into a running photocatalytic reactor. Synthetic air, $\mathrm{O}_{2}$, and $\mathrm{N}_{2}$ bubbles in the size range of 40 to $700 \mathrm{~nm}$ were added to a reaction system comprising $\mathrm{P} 25 \mathrm{TiO}_{2}$ photocatalyst in stirred aqueous solution excited by UV-A lamps, with methyl orange as a target contaminant. The removal of methyl orange was tested under conditions of changing $\mathrm{pH}$ and with the addition of different radical scavengers. Results indicated that the oxygen and air nanobubbles improved the photocatalytic degradation of methyl orange- the removal efficiency of methyl orange increased from $58.2 \pm 3.5 \%$ ( $\mathrm{N}_{2}$ aeration) to $71.9 \pm 0.6 \%\left(\mathrm{O}_{2}\right.$ aeration). Dissolved oxygen (DO) of $14.93 \pm 0.13 \mathrm{mg} / \mathrm{L}$ was achieved using $\mathrm{O}_{2}$ nanobubbles in comparison to $8.43 \pm 0.34 \mathrm{mg} / \mathrm{L}$ without aeration. The photodegradation of methyl orange decreased from $70.8 \pm 0.4 \%$ to $53.9 \pm 0.5 \%$ as $\mathrm{pH}$ increased from 2 to 10 . Experiments using the scavengers showed that $\mathrm{O}_{2}{ }^{-}$was the main reactive species in photocatalytic degradation under highly dissolved oxygen conditions, which also accounted for the observation that the removal efficiency for methyl orange decreased at higher $\mathrm{pH}$. However, without photocatalyst, nanobubbles alone did not improve the removal of methyl orange, and nanobubbles also did not increase the degradation of methyl orange by only photolysis. These experiments show that oxygen and air nanobubbles can act as environmentally friendly catalysts for boosting the performance of photocatalytic water treatment systems.
\end{abstract}

Keywords: nanobubbles; photocatalysis; $\mathrm{TiO}_{2}$; methyl orange; dissolved oxygen; scavenger

\section{Introduction}

Despite decades of research, photocatalysis has not made the jump from academic research to widespread use in water treatment and consumer products. Further progress requires analysis of the factors limiting the performance with the goal of enabling the technology transfer. In use, photocatalytic pollution control relies on the irradiation of a photocatalyst resulting in the production of an electron-hole pair. These primary products react to produce a cascade of secondary reactive species. Many of the details concerning these species, such as their rate of production, concentration, lifetime, and mutual interactions, are only known in broad outline. Going into detail, in the idealized oxidative view, conduction band electrons $\left(e^{-} c b\right)$ react with $\mathrm{O}_{2}$ to form $\mathrm{O}_{2}{ }^{\bullet-}$, and valence band holes $\left(h^{+}\right)$ react with $\mathrm{H}_{2} \mathrm{O}$ to form $\bullet \mathrm{OH}$ [1]. Then, $\mathrm{O}_{2}{ }^{\bullet-}$ and $\bullet \mathrm{OH}$ react with organic compounds. While $h^{+}$and $e^{-}{ }_{c b}$ could react directly with pollutants, dissolved oxygen and especially water are likely to be at much higher concentrations than other components and will react first. Reductive photocatalysis can occur in anoxic solution, wherein reactions of $e^{-} c b$ are 
the main drivers of contaminant degradation [2]. The loss of reactive radicals to side and self-reactions (Figure 1), including the recombination of $e^{-} c b$ and $h^{+}$, is the largest factor limiting the performance and efficiency of photocatalysts [3,4].

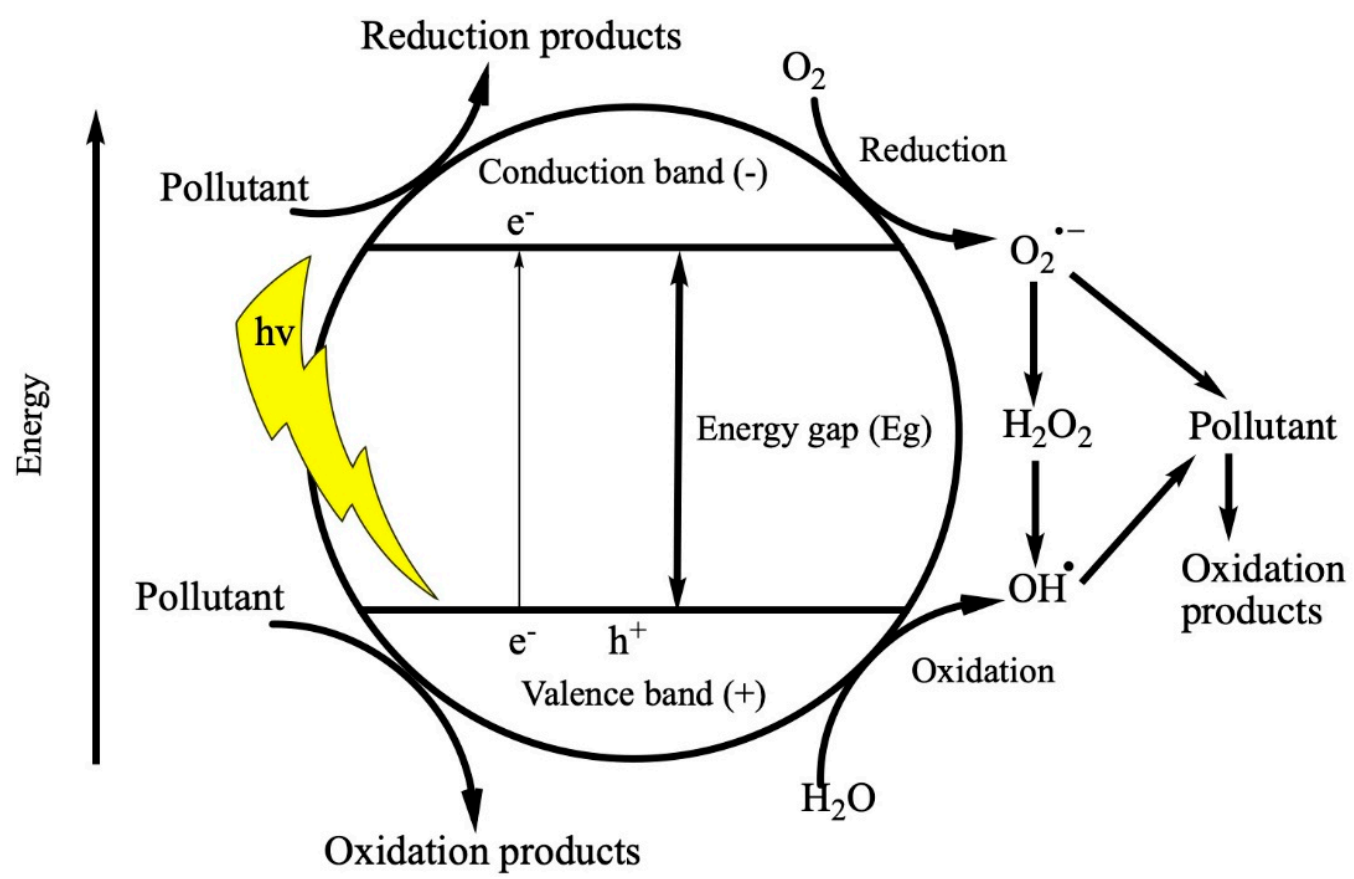

Figure 1. Direct and indirect photocatalytic degradation mechanisms of pollutants in water.

Researchers have tried many methods to prevent the recombination of $e^{-} c b$ and $h^{+}$ with some success; for example, composite materials have been developed that join wide and narrow band gap photocatalysts [5-9] with the different regions acting as sources and reservoirs of $e^{-}{ }_{c b}$. In addition, defects on the surface of photocatalysts can trap $e^{-} c b$ and prevent them from diffusing to stationary $h^{+}[10,11]$. One strategy to prevent the recombination of $e^{-} c b$ and $h^{+}$is to trap the excitation in another form. The requirements were to generate species with sufficiently long lifetime and reactivity with target compounds. The strategy would be to prevent recombination of $e^{-}{ }_{c b}$ and $h^{+}$by converting them into other species, for example, $\mathrm{O}_{2}$ trapping $e^{-}$as superoxide, $\mathrm{O}_{2}{ }^{\bullet-}$.

In addition to chemical species, physical structures including phase boundaries should be included in the discussion. Neppolian et al. [12] showed that reactions on the surfaces of bubbles, including $\bullet \mathrm{OH}$ reactions, accelerate the photocatalytic degradation of dodecylbenzensulfonate. It had also been suggested that the higher the $\mathrm{O}_{2}$ concentration in the solution, the higher the pollutant degradation efficiency. Fotiou et al. [13] reported that when $\mathrm{O}_{2}$ was saturated in the solution, the performance of photocatalysts improved. Wöhrle et al [14] showed that DO was the main oxygen source in the photocatalytic oxidation of benzene to phenol. Zhang et al. [15] showed that $\mathrm{O}_{2}$ plays an important role in the photocatalytic oxidation of alcohols. Overall, on the basis of these studies, there is good evidence that dissolved oxygen is a key component of photocatalytic activity [16]. However, the DO level in water is limited not just by its equilibrium with the atmosphere, but also transport into the bulk solution. As a result, most previous studies have been performed within a narrow range of DO values, and no studies have tested the effect of DO on the photocatalytic oxidation under supersaturation conditions.

Nanobubbles introduce a unique chemical environment that can be used to test theories regarding the mechanisms and bottlenecks of photocatalysis. Nanobubbles provide abundant surface interface for a small amount of material, and in addition change the chemical composition of the bulk solution [17]. The Kelvin equation describes the vapor pressure of a curved surface such as a bubble of gas in a liquid [18]. Moreover, because 
of surface tension, the pressure inside a bubble increases with curvature and increases as the inverse of bubble radius. Very high pressures can be achieved. For example, according to the Young-Laplace equation, the pressure inside a $100 \mathrm{~nm}$ bubble in water is $1.54 \mathrm{MPa}$ or over 15 bar [19]. Nanobubbles have minimal buoyancy due to their small volume and can remain suspended in solution indefinitely, allowing their dispersion throughout the bulk solution.

The rate of oxygen transfer into water depends on the mass transfer coefficient and the area of the gas-water interface [17]. Nanobubbles have a higher interfacial area per volume of gas than micrometer or larger bubbles, which results in higher rate of transfer into water. Research has shown that by using nanobubbles, the mass transfer rate into water for low solubility gases such as $\mathrm{O}_{2}$ and ozone can double [20,21]. Unique chemistry occurs on a bubble surface, and high gas pressure can counteract local depletion in DO [17]; equilibrium between the gas and the solution is rapid, occurring in under a second.

The goal of this paper was to test the limits and mechanism of photocatalytic efficiency by using nanobubbles to impact the recombination of $e^{-} c b$ and holes, due to increased trapping of $e^{-}{ }_{c b}$ as $\mathrm{O}_{2}{ }^{\bullet-}$ as a consequence of enhanced $\mathrm{DO}$, or because of the trapping of $e^{-}{ }_{c b}$ or other reactive species on bubble surfaces. The experiments used nano-particulate titanium dioxide dispersed in water solution containing an organic indicator dye (methyl orange). Conditions such as $\mathrm{pH}$, addition of scavengers, and presence and composition of nanobubbles were varied. Photochemistry was initiated using UV-A lamps, and the concentration of methyl orange was measured at regular intervals to establish photocatalytic activity.

\section{Results and Discussion}

\subsection{Bubble Size Distribution and DO Level}

Several methods are available for making nanobubbles including hydrodynamic cavitation, particle cavitation, acoustic sonication, electrochemical cavitation, and mechanical agitation. In this study, hydrodynamic cavitation resulted as a consequence of high flow velocity caused by the release of a high-pressure gas through a small orifice. As described by Bernoulli's equation, the total pressure is conserved and if the dynamic pressure is increased the static pressure decreases accordingly. If it is lower than the vapor pressure of the liquid, cavitation results.

$$
P_{S}+\frac{\rho V^{2}}{2}=P_{0}
$$

where $P_{S}$ is the static pressure, $\rho$ the density, $V$ the flow velocity, $\rho V^{2} / 2$ the dynamic pressure, and $P_{0}$ the total pressure to remain constant [22].

Bubbles generated by the ceramic diffuser were mainly from 40 to $700 \mathrm{~nm}$. Oxygen gas was seen to form smaller nanobubbles $(40-700 \mathrm{~nm})$ than air $(200-700 \mathrm{~nm})$. The size distributions are shown in Figure 2. The bubbles generated in this work had size distributions comparable with the bubbles generated in other studies using water circulation techniques in bubble generators (Table 1). It should be noted that most previous studies have prepared nanobubble solutions via generators that require circulation of the solution within the system, which can run only in batch-mode. In this study, however, the use of the ceramic diffuser is less complex and allows the continuous addition of nanobubbles to a running reaction. 


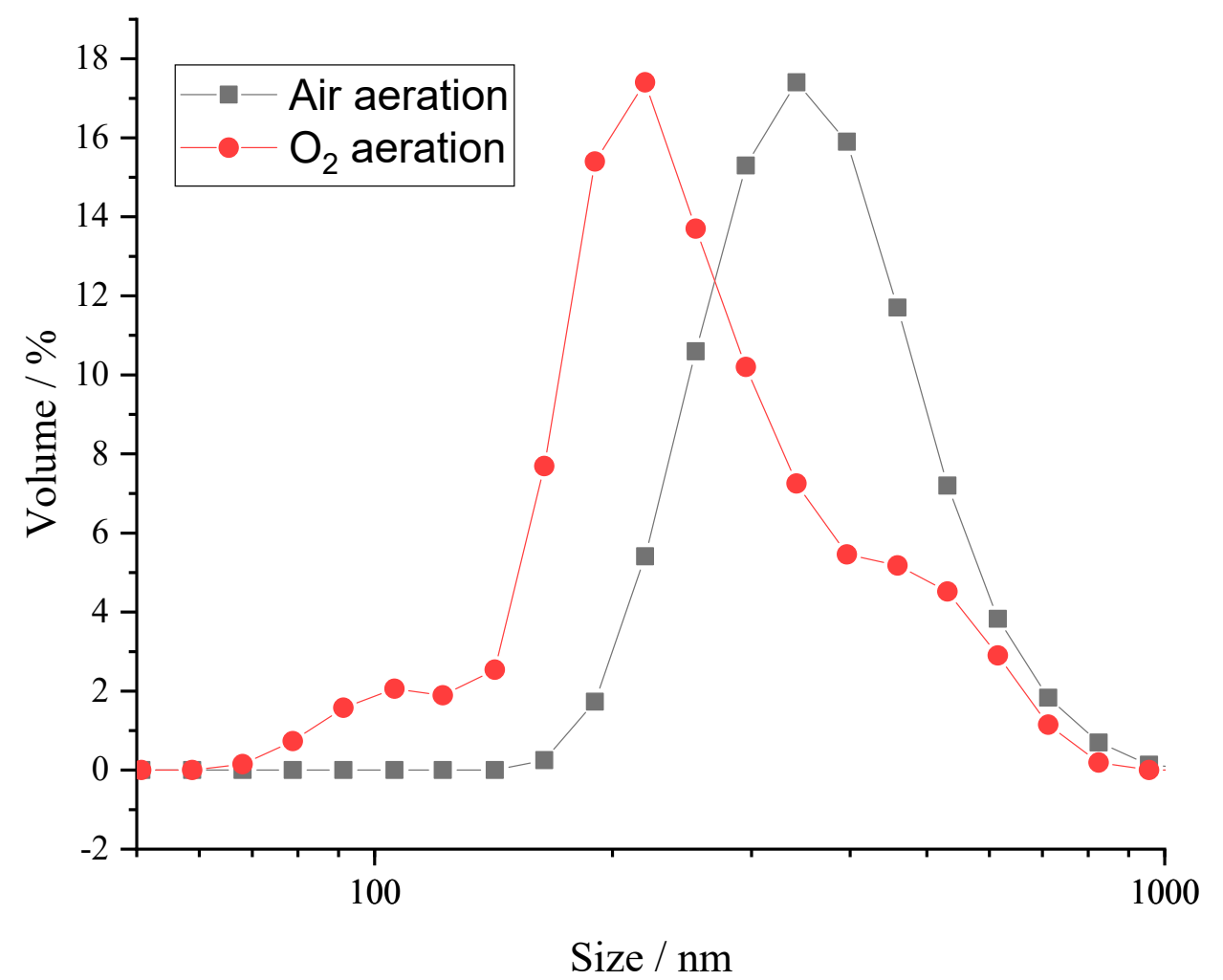

Figure 2. Size distribution of oxygen bubbles and air nano-bubbles generated by the ceramic plate diffuser. The results shown are the average of 3 measurements using a Zetasizer.

Table 1. Size ranges and DO concentration of bubbles generated using different gases.

\begin{tabular}{cccc}
\hline Gas & $d_{\text {bubble }} / \mathbf{n m}$ & DO/mg/L & Reference \\
Air & $140-350$ & 10.7 & {$[23]$} \\
$\mathrm{O}_{2}$ & $137-380$ & 39.6 & \\
$\mathrm{Air}$ & $20-204$ & - & {$[24]$} \\
$\mathrm{O}_{2}$ & $67-159$ & - & \\
$\mathrm{N}_{2}$ & $38-166$ & - & {$[25]$} \\
$\mathrm{O}_{2}$ & $100-500$ & 30.0 & {$[26]$} \\
$\mathrm{Air}$ & $400-6990$ & 9.3 & This study \\
$\mathrm{Air}$ & $200-700$ & 8.7 & \\
$\mathrm{O}_{2}$ & $40-700$ & 14.9 & \\
\hline
\end{tabular}

Using different gases, the solutions showed different DO levels. The highest DO was in the $\mathrm{O}_{2}$ aerated solution, which was $14.93 \mathrm{mg} / \mathrm{L}$, while the least saturated $\mathrm{DO}$ was generated by $\mathrm{N}_{2}$ bubbling $(6.53 \mathrm{mg} / \mathrm{L})$ (the air equilibrated $\mathrm{O}_{2}$ concentration was $8.18 \mathrm{mg} / \mathrm{L}$ ). Compared to nanobubbles generated by generators with hydrodynamic cavitation method, the ceramic diffusor that is used in this study could not result in as high of a pressure as the pump provides $(0.6 \mathrm{MPa})$, and thus it did not reach as high of a DO concentration as with the nanobubble generator; however, it provides a lower cost (Price: $\approx 166 \mathrm{USD}, 0 \mathrm{~W}$ ) compare to nanobubble generators (Price: $\approx 2000$ USD, $\geq 3 \mathrm{~kW}$ ) and continuous bubbling.

\subsection{Effect of Applied Gasses on the Degradation}

Figure 3 shows the results of methyl orange photodegradation catalyzed by $\mathrm{TiO}_{2}$ with different gas types bubbling continuously and at neutral $\mathrm{pH}$ conditions. Control tests were performed using only $\mathrm{TiO}_{2}$ or with air, $\mathrm{O}_{2}$, or $\mathrm{N}_{2}$ bubbles without $\mathrm{TiO}_{2}$. The pseudo-first-order rate was calculated using the following equation: 


$$
k_{1}=\frac{k_{c}^{\prime} K_{\mathrm{O}_{2}}\left[\mathrm{O}_{2}\right]}{1+K_{\mathrm{O}_{2}}\left[\mathrm{O}_{2}\right]}
$$

where $k_{1}$ is the pseudo-first-order rate constant $\left(\mathrm{min}^{-1}\right)$ of methyl orange photodegradation (apparent first order reaction rate constant), $k_{c}^{\prime}$ is the intrinsic rate constant $\left(\mathrm{min}^{-1}\right)$ [27] for methyl orange photodegradation, and $K_{\mathrm{O}_{2}}$ is Langmuir adsorption constant of oxygen over $\mathrm{TiO}_{2}$ surface $\left(\mathrm{L} \mathrm{mg}^{-1}\right)$.
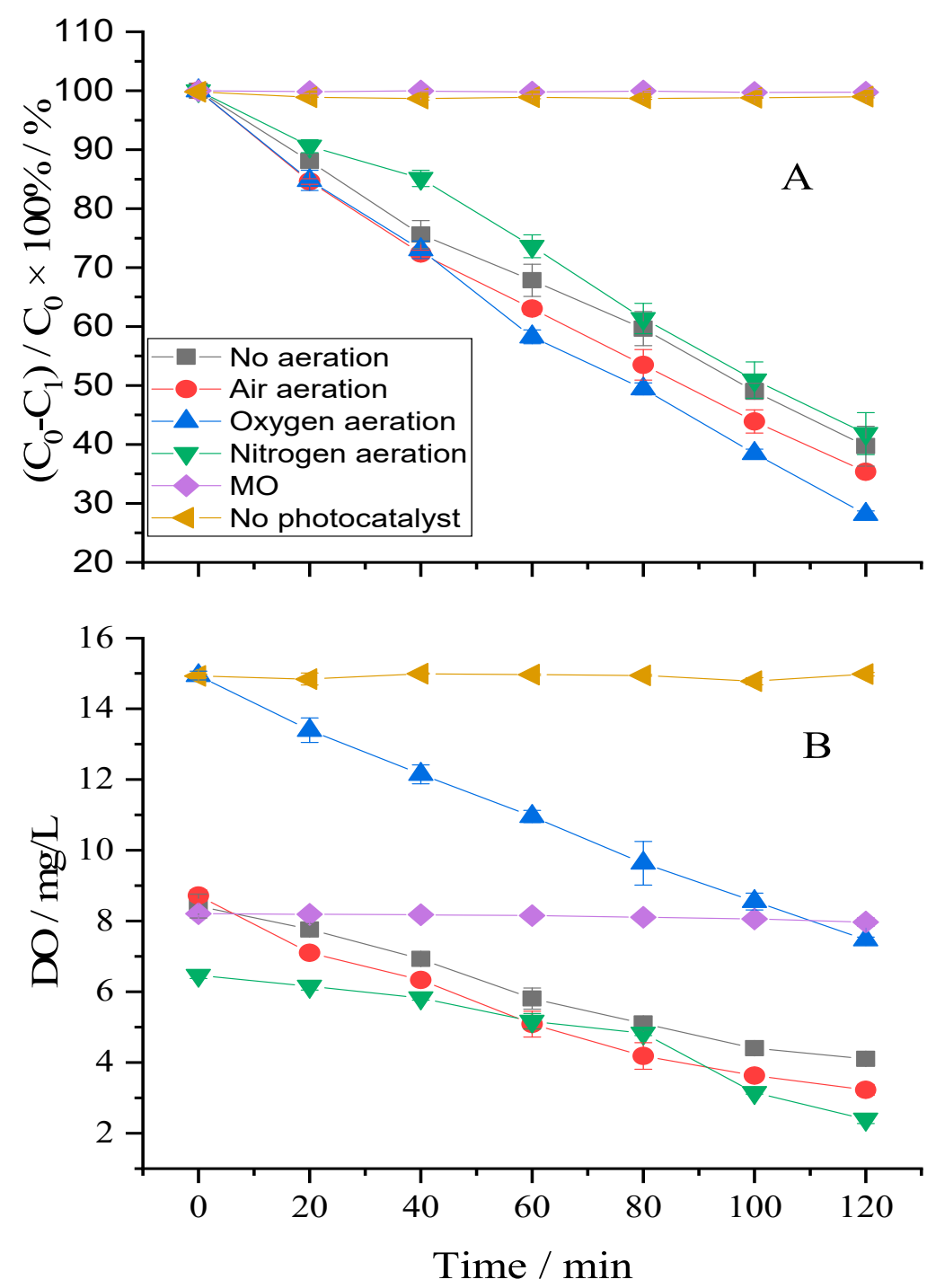

Figure 3. (A) Photocatalytic degradation of methyl orange with nanobubbling at neutral $\mathrm{pH}$. (B) The disappearance of dissolved oxygen during the experiment in the presence of different gas-aerated nanobubbles at neutral $\mathrm{pH}$. Air: air aeration, $20 \mathrm{mg} \mathrm{L}^{-1}$ methyl orange, $2 \mathrm{~g} \mathrm{~L}^{-1} \mathrm{TiO}_{2}$; oxygen: oxygen aeration, $20 \mathrm{mg} \mathrm{L}^{-1}$ methyl orange, $2 \mathrm{~g} \mathrm{~L}^{-1} \mathrm{TiO}_{2}$; nitrogen: $\mathrm{N}_{2}$ aeration, $20 \mathrm{mg} \mathrm{L}^{-1}$ methyl orange, $2 \mathrm{~g} \mathrm{~L}^{-1} \mathrm{TiO}_{2}$; no aeration: $20 \mathrm{mg} \mathrm{L}^{-1}$ methyl orange, $2 \mathrm{~g} \mathrm{~L}^{-1} \mathrm{TiO}_{2} ; \mathrm{MO}$ : without aeration and $\mathrm{TiO}_{2}$. No photocatalytst: $20 \mathrm{mg} \mathrm{L}{ }^{-1}$ methyl orange, oxygen aeration. All experiments include UVA radiation. The results shown are the average of 3 measurements, and the error bars are standard deviation of triplicated experiments.

The methyl orange removal efficiencies with $\mathrm{O}_{2}$, air, and $\mathrm{N}_{2}$ bubbling after $2 \mathrm{~h}$ of irradiation were $71.9 \pm 0.6 \%, 64.7 \pm 0.3 \%$, and $58.2 \pm 3.5 \%$, corresponding to the pseudofirst order reaction rate constants $\left(k_{1}\right)$ of $10.3 \pm 0.1 \times 10^{-3}, 8.5 \pm 0.3 \times 10^{-3}$, and $7.3 \pm 0.7$ $\times 10^{-3} \mathrm{~min}^{-1}$, respectively. Without gas aeration the removal efficiency was $60.3 \pm 3.4 \%$ with a pseudo-first-order reaction rate constant of $7.5 \pm 0.6 \times 10^{-3} \mathrm{~min}^{-1}$. The experiment 
showed negligible removal of methyl orange in dark environment or under light irradiation, which aligned with other studies [28].

With the assistance of $\mathrm{O}_{2}$ nano-bubbles, the photocatalytic performance of $\mathrm{TiO}_{2}$ increased $11.6 \%$ compared to no bubbling, and with $\mathrm{N}_{2}$ aeration, the removal of methyl orange was slightly decreased $(-1.9 \%)$. The observed results could be due to the following factors: (a) dissolved oxygen helps increase photocatalytic oxidation; (b) nanobubble collapse increases photocatalytic oxidation; (c) the nanobubble surfaces modify the concentrations of reactive species acting both as a reservoir and a catalyst. On the basis of the evidence, we can strike option ' $b$ ' from the list, while research has shown that during the process of nanobubble collapse, reactive radicals such as $\bullet \mathrm{OH}$ are generated [29]. However, in our study, $\mathrm{O}_{2}$ nanobubbles alone did not degrade methyl orange. Thus, there was no evidence that nanobubbles themselves have oxidation potential, but they can act as co-catalysts.

Reactive oxygen species (ROS) include short-lived radical species such as hydroxyl $(\bullet \mathrm{OH})$, superoxide $\left(\mathrm{O}_{2}{ }^{\bullet-}\right)$, and singlet oxygen $\left({ }^{1} \mathrm{O}_{2}\right)$. Of these, only $\bullet \mathrm{OH}$ has been reported to coexist with nanobubbles [30]; the existence of other ROS species has not been reported $\left(\mathrm{H}_{2} \mathrm{O}_{2},{ }^{1} \mathrm{O}_{2}, \mathrm{O}_{2}{ }^{\bullet-}\right)$. Liu et al reported $10^{14} \bullet \mathrm{OH}$ molecule per milliliter were generated from nanobubbles [31]; however, this was questioned by Yasui et al. as their numerical simulation suggested that only a few $\bullet \mathrm{OH}$ may be created per $10^{7}$ dissolving $\mathrm{O}_{2}$ nanobubbles without dynamic stimuli [32]. In our study, without photocatalysts, there was no removal of methyl orange by using only nanobubbles and light irradiation observed; however, with the presence of air and $\mathrm{O}_{2}$ nanobubbles, the photocatalytic degradation of methyl orange increased (with $\mathrm{TiO}_{2}$ and light irradiation).

DO concentrations decreased during the experiments due to the consumption of dissolved oxygen by the reaction (Figure 3B). The initial DO for air aeration and no aeration were similar; however, with air nanobubble aeration, the removal efficiency of methyl orange, $64.7 \pm 0.3 \%$, was higher than for no aeration, $60.3 \pm 3.4 \%$. This result showed that introducing nanobubbles into the system enhanced the photocatalytic efficiency of degrading methyl orange. The depletion rate of dissolved oxygen was calculated by linear fitting. The absolute value of the depletion rate of dissolved oxygen was $6.16 \times 10^{-2}$, $2.60 \times 10^{-2}, 4.30 \times 10^{-2} \mathrm{mg} /(\mathrm{L} \mathrm{min})$ in $\mathrm{O}_{2-}, \mathrm{N}_{2^{-}}$, and air-saturated solution, respectively. Without aeration, the rate was $3.86 \times 10^{-2} \mathrm{mg} /(\mathrm{L} \mathrm{min})$. With neither $\mathrm{TiO}_{2}$ nor aeration, or without $\mathrm{TiO}_{2}$ but with $\mathrm{O}_{2}$ aeration, the depletion rate was close to 0 . This result indicates there was no consumption of DO. The $\mathrm{O}_{2}$-saturated solution showed fastest $\mathrm{DO}$ depletion rate along with the largest $k_{1}$. The consumption rate of dissolved oxygen and removal efficiency of methyl orange were correlated (Pearson's correlation coefficient 0.9977$)$. This indicates that dissolved oxygen plays an important role in methyl orange removal.

\subsection{The Role of Reactive Species in the Degradation Mechanisms}

According to the established mechanisms of photocatalysis, the key reactive species are the photogenerated $h^{+}$and $e^{-}{ }_{c b}$, and reactive radical species such as $\mathrm{O}_{2}{ }^{\bullet-}$ and $\bullet \mathrm{OH}$ [33]. The contributions of the separate reactive species for pollutant removal can be identified using specific scavengers. All experiments were performed at neutral $\mathrm{pH}$. The characterization of the reactive species was performed by introducing radical scavengers into the system.

Potassium iodide (KI) $[34,35]$ was used as the $h^{+}$and $\bullet \mathrm{OH}$ radical scavenger. Sodium nitrate $\mathrm{NaNO}_{3}$ was used as the $e^{-}{ }_{c b}$ scavenger [36], tert-butyl alcohol (TBA) [37,38] was the $\bullet \mathrm{OH}$ scavenger, and p-benzoquinone (pBQ) $[39,40]$ was the $\mathrm{O}_{2}{ }^{\bullet-}$ scavenger. During the tests, a $5.5 \mathrm{mM}$ aliquot of a single scavenger was added into solution with $20 \mathrm{mg} \mathrm{L}^{-1}$ methyl orange and $2 \mathrm{~g} \mathrm{~L}^{-1} \mathrm{TiO}_{2}$ to monitor the change of methyl orange removal efficiency compared with the results from tests without scavengers.

As shown in Figure 4, the inhibition effects of $\mathrm{KI}, \mathrm{TBA}, \mathrm{NaNO}_{3}$, and $\mathrm{pBQ}$ without aeration were $28.2 \%, 47.0 \%, 26.5 \%$, and $24 \%$, respectively. 


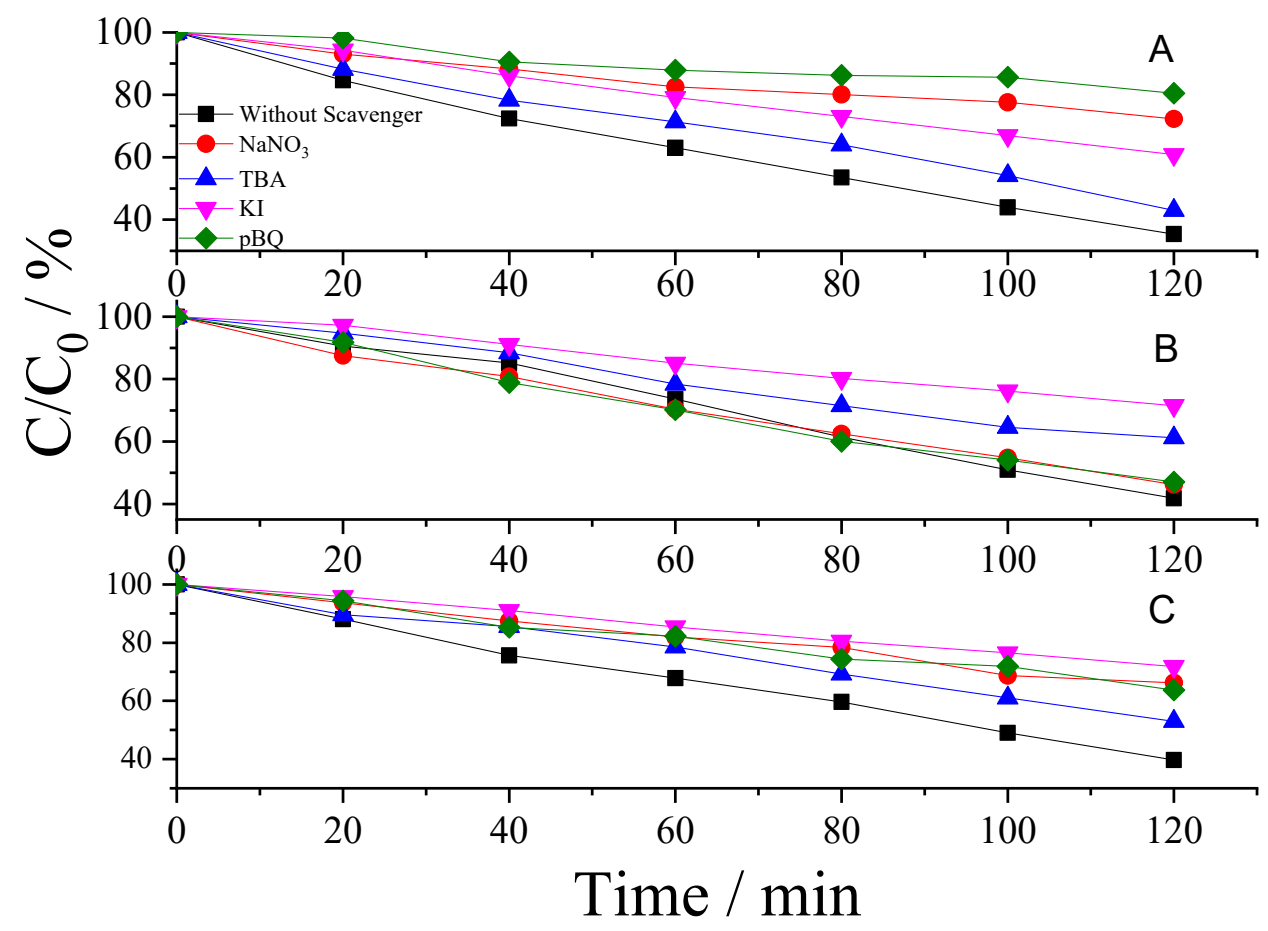

Figure 4. The effects of scavengers on the photodegradation of methyl orange without aeration (conditions: $20 \mathrm{mg} \mathrm{L}^{-1}$ methyl orange, $2 \mathrm{~g} \mathrm{~L}^{-1} \mathrm{TiO}_{2}$, UVA irradiation, neutral $\mathrm{pH}$ ). (A): Air bubbling; (B): $\mathrm{N}_{2}$ bubbling; (C): no aeration. Potassium iodide (KI): $h^{+}$and $\bullet \mathrm{OH}$ scavengers, sodium nitrate $\left(\mathrm{NaNO}_{3}\right): e^{-}{ }_{c b}$ scavenger, tert-butyl alcohol (TBA): $\bullet \mathrm{OH}$ scavenger, and p-benzoquinone (pBQ): $\mathrm{O}_{2}^{\bullet-}$ scavenger.

As shown in Table 2, the pseudo-first-order reaction rate constant $k_{1}$ decreased to $0.0017 \mathrm{~min}^{-1}$ when $\mathrm{pBQ}$ was added, thus indicating the $\mathrm{O}_{2}{ }^{\bullet-}$ played a predominant role in the air nanobubble photocatalytic degradation of methyl orange. With the addition of $\mathrm{NaNO}_{3}, k_{1}$ decreased to $0.0026 \mathrm{~min}^{-1}$, which we interpret as demonstrating $e^{-} b$ is another major active species of air nanobubble photocatalytic degradation of methyl orange. With $h^{+}$ and $\bullet \mathrm{OH}$ together, $k_{1}$ decreased to $0.0042 \mathrm{~min}^{-1}$ while with only $\bullet \mathrm{OH}, k_{1}$ was $0.0066 \mathrm{~min}^{-1}$. With $\mathrm{N}_{2}$ aeration, $h^{+}$and $\bullet \mathrm{OH}$ play a dominant role due to the low dissolved oxygen in the solution.

Table 2. Comparison of different gas aeration methods and decrease in the apparent first-order reaction rate constant $k_{1}$ (/min) for different scavengers (20 mg L ${ }^{-1}$ methyl orange, $\left.2 \mathrm{~g} \mathrm{~L}^{-1} \mathrm{TiO}_{2}, \mathrm{UVA}\right)$.

\begin{tabular}{|c|c|c|c|c|}
\hline & $\begin{array}{c}\text { Target Reactive } \\
\text { Species }\end{array}$ & $\begin{array}{c}k_{1} \text { for } \mathrm{No} \\
\text { Aeration } / \mathrm{min}^{-1}\end{array}$ & $\begin{array}{c}k_{1} \text { for } \mathrm{Air} \\
\text { Aeration } / \mathrm{min}^{-1}\end{array}$ & $\begin{array}{c}k_{1} \text { for } \mathrm{N}_{2} \\
\text { Aeration } / \mathrm{min}^{-1}\end{array}$ \\
\hline Without scavengers & & $7.5 \times 10^{-3}$ & $8.5 \times 10^{-3}$ & $7.3 \times 10^{-3}$ \\
\hline KI & $h^{+}$and $\bullet \mathrm{OH}$ & $2.8 \times 10^{-3}$ & $4.2 \times 10^{-3}$ & $2.9 \times 10^{-3}$ \\
\hline TBA & $\bullet \mathrm{OH}$ & $5.1 \times 10^{-3}$ & $6.6 \times 10^{-3}$ & $4.4 \times 10^{-3}$ \\
\hline $\mathrm{NaNO}_{3}$ & $e^{-} c b$ & $3.5 \times 10^{-3}$ & $2.6 \times 10^{-3}$ & $6.3 \times 10^{-3}$ \\
\hline $\mathrm{pBQ}$ & $\mathrm{O}_{2}^{-}$ & $3.6 \times 10^{-3}$ & $1.7 \times 10^{-3}$ & $6.4 \times 10^{-3}$ \\
\hline
\end{tabular}

Without aeration, $\mathrm{O}_{2}^{\bullet-}$ and $e^{-}{ }_{c b}$ are dominant, making similar contributions to the methyl orange removal. With these conditions, they are more important than $h^{+}$and $\bullet \mathrm{OH}$.

The large decrease in the methyl orange removal efficiency when using $\mathrm{pBQ}$ in air aeration and $\mathrm{O}_{2}$ aeration shows that the dominant reactive species of methyl orange degradation in an oxygenated environment was $\mathrm{O}_{2}^{\bullet-}$, in accordance with other reports (Table 3). 
Table 3. Comparison of effect of different reactive species in other studies.

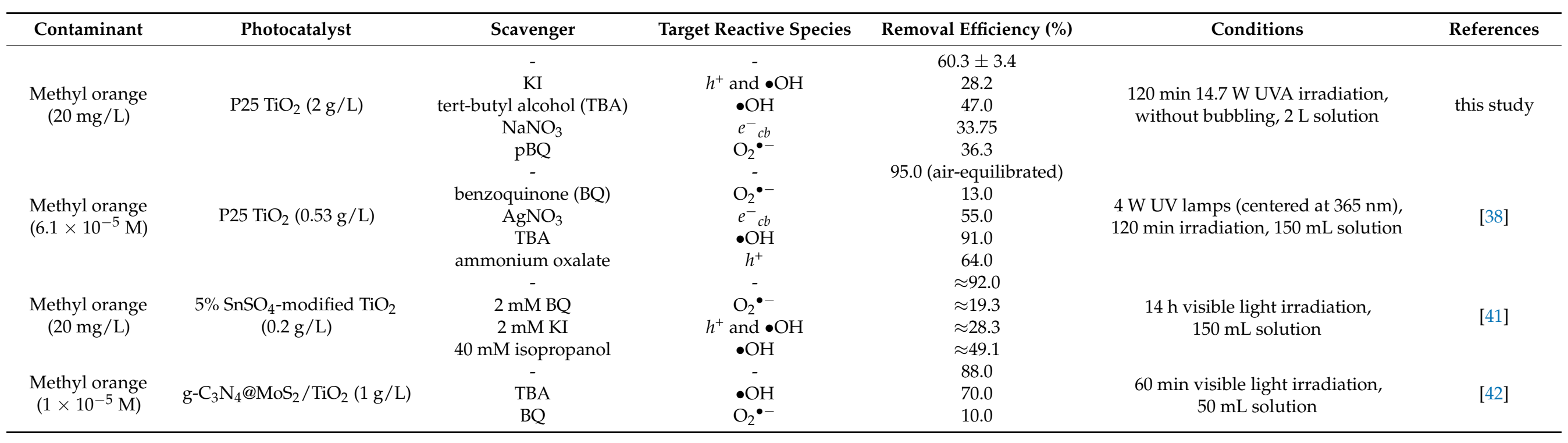


Therefore, we conclude that photogenerated $h^{+}$and $\bullet \mathrm{OH}$ together make the main contribution towards oxidizing methyl orange, both with and without nano-bubbling, while $\mathrm{O}_{2}{ }^{--}$was the main reactive oxidizing reagent in a dissolved oxygen-rich environment. In $\mathrm{N}_{2}$ nanobubble photocatalytic degradation, $\bullet \mathrm{OH}$ contributed most to the degradation of methyl orange. A study by Temesgen et al. showed that the surfaces of nanobubbles are negatively charged with $\mathrm{OH}^{-}$from the water molecules [22], which might provide the reactive species in a low dissolved oxygen environment.

Wang et al. [25] reported over $60 \%$ of oxytetracycline (OTC) was directly photodegraded $\left(k=3.92 \times 10^{-3} \mathrm{~min}^{-1}\right)$ in the presence of only $\mathrm{O}_{2}$ nanobubbles with sizes in the range from 100 to $500 \mathrm{~nm}$ after $240 \mathrm{~min}$ of visible light. In their study, $\bullet \mathrm{OH}$ was shown to be the main reactive species of OTC degradation, and $20 \%$ of OTC would degrade with only photolysis. The main reactive species for degrading methyl orange was found to be $\mathrm{O}_{2}{ }^{\bullet-}$ in the present work; our study showed no degradation with only $\mathrm{O}_{2}$ nanobubbles and photolysis. This might suggest that different pollutants undergo different degradation mechanism, and that adding $\mathrm{O}_{2}$ nanobubbles for water treatment may not affect the degradation of all pollutants similarly.

\subsection{Effect of $p H$}

The $\mathrm{pH}$ value had a critical effect on the efficiency of photocatalytic reactions. The influence of solution $\mathrm{pH}$ on the process was determined using a constant concentration of methyl orange at $20 \mathrm{mg} \mathrm{L}^{-1}, 2 \mathrm{~g} \mathrm{~L}^{-1} \mathrm{TiO}_{2}$ with $\mathrm{O}_{2}$ nanobubbles, and without bubbling by varying $\mathrm{pH}$ from 2 to 10 . The results are shown in Figure 5 and Table 4 . The lowest removal efficiency for methyl orange was detected at $\mathrm{pH}=10$ with and without bubbling, and the highest removal efficiency was found at $\mathrm{pH}=2$ and $\mathrm{pH}=5$ for no bubbling and air bubbling, respectively.

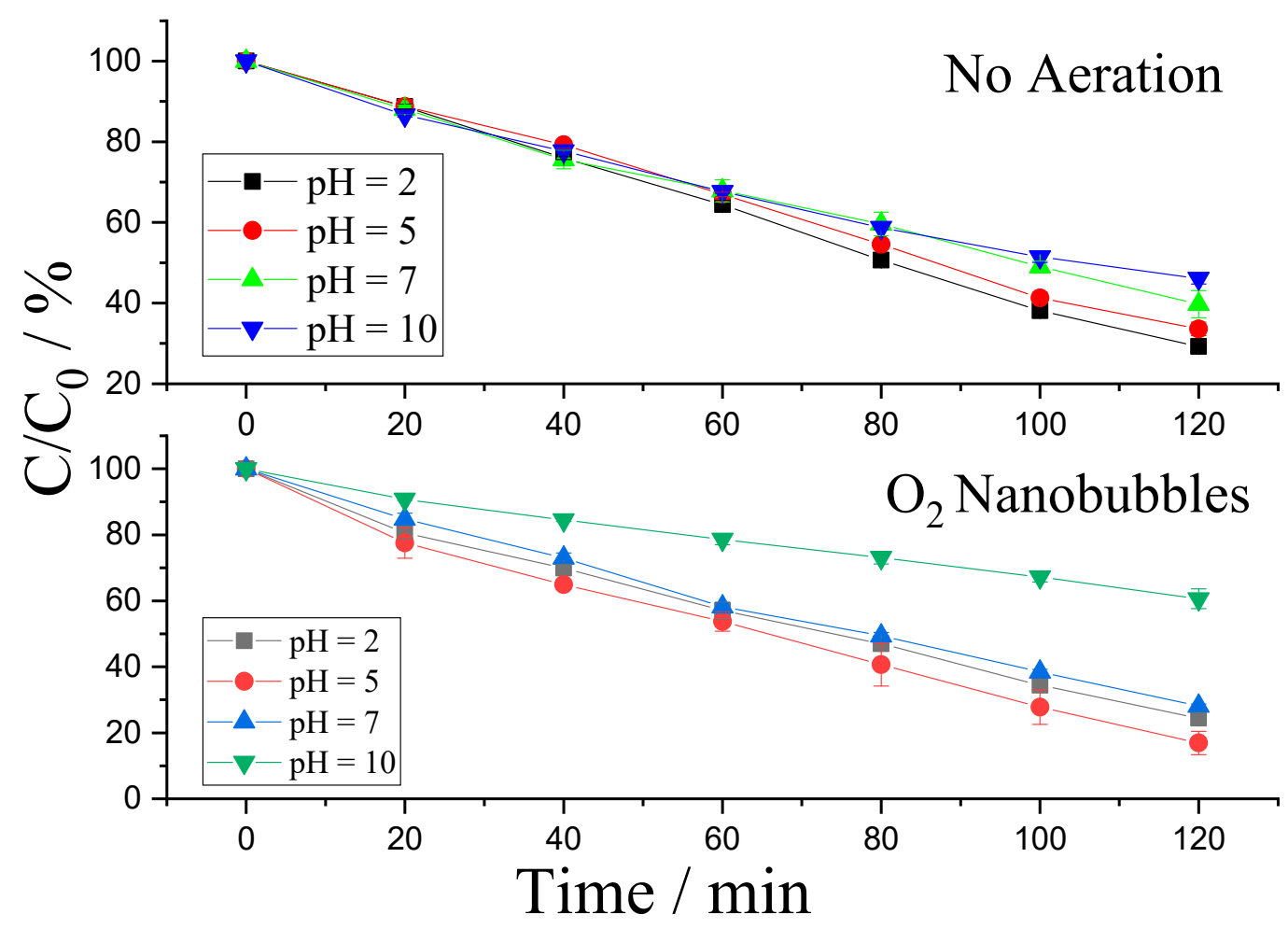

Figure 5. Photocatalytic degradation of methyl orange at different $\mathrm{pH}$ values with oxygen nanobubbles (conditions: $20 \mathrm{mg} \mathrm{L}^{-1}$ methyl orange, $2 \mathrm{~g} \mathrm{~L}^{-1} \mathrm{TiO}_{2}, 14.7 \mathrm{~W}$ UVA irradiation).

The methyl orange (MO) adsorption efficiency of $\mathrm{TiO}_{2}$ is significantly impacted by the changing electrostatic interaction between $\mathrm{TiO}_{2}$ and $\mathrm{MO}$ under the different $\mathrm{pH}$ conditions [43]. The adsorption efficiency values at different $\mathrm{pH}$ values are summarized in 
Table 5. The highest adsorption capacity $(31.0 \pm 4.2 \%)$ was observed at $\mathrm{pH}=5$, while no $\mathrm{MO}$ adsorption occurred on the surface of $\mathrm{TiO}_{2}$ at $\mathrm{pH}=10$. These differences resulted from the changes in the charge of $\mathrm{MO}$ and the surface charge of $\mathrm{TiO}_{2}$ particles. The point of zero charge of $\mathrm{TiO}_{2}$ is at $\mathrm{pH}=5.8 \pm 0.1$ [44]; if the $\mathrm{pH}$ is more acidic than this value, the surface is positively charged, $\mathrm{TiO}_{2}+\mathrm{H}^{+} \rightarrow \mathrm{TiO}_{2} \mathrm{H}^{+}$, and if $\mathrm{pH}$ is above this value, it is negatively charged, $\mathrm{TiO}_{2}+\mathrm{OH}^{-} \rightarrow \mathrm{TiO}_{2} \mathrm{OH}^{-}$[45]. Thus, at acidic $\mathrm{pH}$ values, negatively charged nanobubbles will be attracted to the surface. The methyl orange indicator has a $\mathrm{pKa}$ value of 3.47. At $\mathrm{pH}$ values above this value, the molecule is negatively charged [46]. In this form there is electrostatic repulsion between the negatively charged $\mathrm{TiO}_{2}$ and negatively charged sulfate group on the azo-form methyl orange, leading to no methyl orange adsorption on the $\mathrm{TiO}_{2}$ surface. Under conditions with $\mathrm{pH}$ below $\mathrm{pKa}$, methyl orange is better adsorbed since the $\mathrm{RSO}_{3}{ }^{-}$is attracted by positively charged surface functionalities. According to the scavenger test the main reactive species for degrading methyl orange is $\mathrm{O}_{2}{ }^{\bullet-}$, while at high $\mathrm{pH}$, the high concentration of $\mathrm{OH}^{-}$may limit the separation of electron-hole pairs, which will further inhibit photocatalytic activity. Since pKa of the $\mathrm{O}_{2}{ }^{\bullet-} / \mathrm{HO}_{2}{ }^{\bullet}$ was 4.8, $\mathrm{HO}_{2}$ may act as a stronger oxidant than $\mathrm{O}_{2}{ }^{\bullet-}$, which could be contributing to the faster MO degradation at $\mathrm{pH}=2$. Compared to other studies (Table 5), at lower $\mathrm{pH}$, the photocatalytic reaction presented the highest removal efficiency in most cases. The trend of the effect of $\mathrm{pH}$ did not change because of higher oxygen dissolved in solution.

At $\mathrm{pH}=10$, the removal decreased compared to no aeration. Nanobubbles were proved to be negatively charged from $\mathrm{pH} 2$ to 12 [22], and the magnitude of the negative zeta potential of nanobubbles increased monotonically as a function of $\mathrm{pH}$. At $\mathrm{pH}=10$, the zeta potential of oxygen nanobubbles could reach to $-32 \mathrm{mV}$, resulting in a negative charge on nanobubble's surface. At low $\mathrm{pH}$, nanobubbles are expected to have a short lifetime due to the lack of $\mathrm{OH}^{-}$ions needed to form a stable electric layer around the bubble surface, while in alkaline solutions, the bubbles are more stable and have a longer lifetime [47]. Agrawal et al. [48] showed that lower $\mathrm{pH}$ enhances the generation of free radicals. Our experimental results confirm these findings.

Table 4. Summary of results for methyl orange photodegradation as a function of $\mathrm{pH}$ (conditions: $20 \mathrm{mg} \mathrm{L}^{-1}$ methyl orange, $\left.2 \mathrm{~g} \mathrm{~L}^{-1} \mathrm{TiO}_{2}, \mathrm{UVA}\right)$.

\begin{tabular}{cccc}
\hline pH & $\begin{array}{c}\text { Methyl Orange Degradation } \\
\text { Efficiency without Aeration/\% }\end{array}$ & $\begin{array}{c}\text { Methyl Orange Photodegradation } \\
\text { Efficiency with } \mathbf{O}_{\mathbf{2}} \text { Bubbling/\% }\end{array}$ & $\begin{array}{c}\text { Methyl Orange Adsorption } \\
\text { Efficiency (\%) }\end{array}$ \\
\hline 2 & $70.8 \pm 0.4$ & $75.6 \pm 1.0$ & $29.4 \pm 2.1$ \\
5 & $66.4 \pm 0.7$ & $83.1 \pm 2.3$ & $31.0 \pm 4.2$ \\
7 & $60.1 \pm 0.4$ & $71.9 \pm 0.6$ & $18.3 \pm 2.5$ \\
10 & $53.9 \pm 0.5$ & $39.4 \pm 1.0$ & $-0.4 \pm 1.3$ \\
\hline
\end{tabular}

Table 5. Comparison of $\mathrm{pH}$ effect with other studies.

\begin{tabular}{|c|c|c|c|c|c|}
\hline Contaminant & Photocatalyst & $\mathrm{pH}$ & Removal Efficiency $/ \%$ & Conditions & Reference \\
\hline $\begin{array}{l}\text { Methyl orange } \\
20 \mathrm{mg} / \mathrm{L}\end{array}$ & $\mathrm{P} 25 \mathrm{TiO}_{2}(2 \mathrm{~g} / \mathrm{L})$ & $\begin{array}{c}2 \\
5 \\
7 \\
10\end{array}$ & $\begin{array}{l}70.8 \pm 0.4 \\
66.4 \pm 0.7 \\
60.1 \pm 0.4 \\
53.9 \pm 0.5\end{array}$ & $\begin{array}{l}120 \text { min } 14.7 \text { W UVA irradiation, } \\
\text { without bubbling, } 2 \text { L solution }\end{array}$ & this study \\
\hline $\begin{array}{l}\text { Methyl orange } \\
10 \mathrm{mg} / \mathrm{L}\end{array}$ & $\mathrm{TiO}_{2} / \mathrm{PW}_{12}$ & $\begin{array}{c}2 \\
4 \\
6.4\end{array}$ & $\begin{array}{l}93.2 \\
54.5 \\
10.0\end{array}$ & $\begin{array}{l}300 \mathrm{~W} \text { medium-pressure mercury } \\
\left.\text { lamp (MPML, } \lambda_{\max }=365 \mathrm{~nm}\right) \\
60 \mathrm{~min} \text { irradiation, } 20 \mathrm{~mL} \text { solution }\end{array}$ & [49] \\
\hline $\begin{array}{l}\text { Methyl orange } \\
20 \mathrm{mg} / \mathrm{L}\end{array}$ & $\mathrm{TiO}_{2} / \mathrm{Cs}-\mathrm{MT}$ & $\begin{array}{c}3 \\
6.3 \\
9\end{array}$ & $\begin{array}{l}93.7 \\
98.0 \\
94.3\end{array}$ & $\begin{array}{l}45 \mathrm{~W} \text { fluorescent lamp, } 60 \mathrm{~min} \\
\text { irradiation, } 20 \mathrm{~mL} \text { solution }\end{array}$ & {$[50]$} \\
\hline $\begin{array}{l}\text { Methyl orange } \\
10 \mathrm{mg} / \mathrm{L}\end{array}$ & Ag-DP25 (0.16 g/L) & $\begin{array}{c}3 \\
5 \\
6.6 \\
9\end{array}$ & $\begin{array}{c}43.0 \\
72.0 \\
100.0 \\
51.0\end{array}$ & $\begin{array}{l}\text { medium-pressure mercury vapor } \\
\text { lamp (350-400 nm), } 60 \mathrm{~min} \\
\text { irradiation, } 250 \mathrm{~mL} \text { solution }\end{array}$ & [51] \\
\hline
\end{tabular}




\section{Materials and Methods}

\subsection{Chemical and Reagents}

UV-A light from 340 to $400 \mathrm{~nm}$ was generated using 1 PL-L 24W/10/4P lamp with light intensity of $4.9 \mathrm{~W}$ of UV-A output from Philips with a maximum intensity at $365 \mathrm{~nm}$. The concentration of methyl orange ( $\mathrm{pH}$ 3.0-4.4, Sigma-Aldrich, St. Louis, MO, USA) was $20 \mathrm{mg} / \mathrm{L}$. The P25 $\mathrm{TiO}_{2}$ was purchased from Sigma-Aldrich (St. Louis, MO, USA, $21 \mathrm{~nm}$ primary particle size, $\geq 99.5 \%$ purity on a trace metals basis) and added at a nominal concentration of $2 \mathrm{~g} / \mathrm{L}$. $\mathrm{O}_{2}$ (Air Liquide, Alphagaz-1, 99.5\%, Taastrup, Denmark), and $\mathrm{N}_{2}$ (Air Liquide, Alphagaz-1, 99.995\%) were used without further purification. Filtered compressed technical air was used as supplied by university facilities. Ceramic micro bubble diffusers (PMBD 75, Point Four Systems, Airoxi, India) were used to produce uniform fine bubbles from 100 to $500 \mathrm{~nm}$, with gas pressures from 1.7 to 2.4 bar [52].

\subsection{Sample Characterization}

The gas bubble size distribution was measured using a Zetasizer (Brookhaven Instruments, Holtsville, NY, USA). The DO concentration and $\mathrm{pH}$ were measured using the Multiparameter Meter edge ${ }^{\circledR}$ from Hanna Instruments, Kungsbacka, Sweden.

\subsection{Experiment Setup}

The photocatalytic activity of $\mathrm{TiO}_{2}$ nanoparticles was quantified by monitoring the photodegradation of methyl orange in aqueous solution with continuous supply of nanobubbles, under UVA irradiation. Photocatalytic tests were carried out using a beaker filled with an aqueous suspension $\left(2 \mathrm{~L}\right.$ ) containing methyl orange, $\mathrm{TiO}_{2}$, and the nanobubble generator with different types of gas; without aeration, pure $\mathrm{N}_{2}$, pure $\mathrm{O}_{2}$, and with clean technical air.

Initially, $20 \mathrm{mg} / \mathrm{L}$ of methyl orange was put into a beaker with Milli-Q water and stirred for $10 \mathrm{~min}$. The $\mathrm{pH}$ of the solution was adjusted using $\mathrm{NaOH}$ or $\mathrm{HCl}$ and measured with the $\mathrm{pH}$ meter. $\mathrm{TiO}_{2}(2 \mathrm{~g} / \mathrm{L})$ was added into a stirred beaker under dark conditions for $30 \mathrm{~min}$. Keeping it in the dark, the nanobubble generator with the selected gas (pure $\mathrm{N}_{2}$, pure $\mathrm{O}_{2}$, or clean technical air; flow rate: $100 \mathrm{~mL} \mathrm{~min}^{-1}$ ) generates nanobubbles with inherently different DO levels. After $30 \mathrm{~min}$, the system was irradiated under UVA light until the initial dissolved oxygen concentration reached a constant level, keeping the solution in a water bath at $23 \pm 2{ }^{\circ} \mathrm{C}$ with continuous magnetic stirring. The UV lamps were immersed in the solution with a light path of $12 \mathrm{~cm}$. Next, samples were taken at specific time intervals. After centrifugal separation, twice at $5000 \mathrm{rpm}$ for $20 \mathrm{~min}$ (Labofuge 200, Heraeus Sepatech GmbH, Oesterode, Germany ), the absorption spectra of methyl orange in supernatant were analyzed with a UV-VIS spectrophotometer (UV-2401 PC, Shimadzu Inc., Columbia, MD, USA).

\section{Conclusions}

We studied the synergistic effect of nanobubbles and $\mathrm{TiO}_{2}$ photocatalysis on the degradation of methyl orange under UVA light for the first time. By adding oxygen nanobubbles, we increased photocatalytic degradation from $58.2 \pm 3.5 \%\left(\mathrm{~N}_{2}\right.$ aeration) to $71.9 \pm 0.6 \%$, whereas without aeration, the removal efficiency was $60.3 \pm 3.4 \%$. This may have been due to increased DO, increased oxygen gas/water surface area, or the presence of oxygen bubbles on the photocatalyst surface. Methyl orange could not be directly degraded by nanobubbles without irradiation or without the photocatalyst, while during the photocatalytic reaction, the consumption of DO may enhance the generation of reactive species, thus improving the removal efficiency. The removal efficiency was greater at acidic $\mathrm{pH}$. Scavenger tests showed that $h^{+}, \bullet \mathrm{OH}, \mathrm{O}_{2}{ }^{\bullet-}$, and $e^{-} c b$ were the reactive species in the methyl orange degradation. The dominant active species in the reaction with high dissolved oxygen condition was $\mathrm{O}_{2}{ }^{\bullet-} / \mathrm{HO}_{2}{ }^{\bullet}$, while in low dissolved oxygen solution, $h^{+}$ and $\bullet \mathrm{OH}$ were the main reactive species. This study suggests that nanobubbles may be a novel method for enhancing the photocatalytic degradation of organic pollutants. 
Author Contributions: Conceptualization, M.S.J., M.A. and W.Y.; methodology, M.S.J., M.A. and W.Y.; experiments, J.C. and W.Y.; validation, M.S.J., M.A. and E.L.C.; formal analysis, J.C., W.Y. and M.A.; writing—original draft preparation, W.Y.; writing—review and editing, W.Y., J.C., E.L.C., M.S.J. and M.A.; supervision, M.S.J., M.A. and E.L.C. All authors have read and agreed to the published version of the manuscript.

Funding: This paper was funded by the Chinese Scholarship Council and the Department of Chemistry of the University of Copenhagen.

Data Availability Statement: The data presented in this study are available on request from the corresponding author. The data are not publicly available due to privacy.

Conflicts of Interest: The authors are aware of no conflicts of interest.

\section{References}

1. Awfa, D.; Ateia, M.; Fujii, M.; Johnson, M.S.; Yoshimura, C. Photodegradation of pharmaceuticals and personal care products in water treatment using carbonaceous- $\mathrm{TiO}_{2}$ composites: A critical review of recent literature. Water Res. 2018, 142, 26-45. [CrossRef]

2. Zhao, B.; Lv, M.; Zhou, L. Photocatalytic degradation of perfluorooctanoic acid with $\beta-\mathrm{Ga}_{2} \mathrm{O}_{3}$ in anoxic aqueous solution. J. Environ. Sci. 2012, 24, 774-780. [CrossRef]

3. Ikeda, S.; Sugiyama, N.; Pal, B.; Marcí, G.; Palmisano, L.; Noguchi, H.; Uosaki, K.; Ohtani, B. Photocatalytic activity of transitionmetal-loaded titanium (IV) oxide powders suspended in aqueous solutions: Correlation with electron-hole recombination kinetics. Phys. Chem. Chem. Phys. 2001, 3, 267-273. [CrossRef]

4. Serpone, N.; Lawless, D.; Khairutdinov, R.; Pelizzetti, E. Subnanosecond relaxation dynamics in $\mathrm{TiO}_{2}$ colloidal sols (particle sizes $\mathrm{Rp}=1.0-13.4 \mathrm{~nm})$. Relevance to heterogeneous photocatalysis. J. Phys. Chem. 1995, 99, 16655-16661. [CrossRef]

5. Xu, J.; Wang, W.; Sun, S.; Wang, L. Enhancing visible-light-induced photocatalytic activity by coupling with wide-band-gap semiconductor: A case study on $\mathrm{Bi}_{2} \mathrm{WO}_{6} / \mathrm{TiO}_{2}$. Appl. Catal. B Environ. 2012, 111, 126-132. [CrossRef]

6. Xing, C.; Zhang, Y.; Yan, W.; Guo, L. Band structure-controlled solid solution of $\mathrm{Cd}_{1-\mathrm{x}} \mathrm{Zn}_{\mathrm{x}} \mathrm{S}$ photocatalyst for hydrogen production by water splitting. Int. J. Hydrogen Energy 2006, 31, 2018-2024. [CrossRef]

7. Hu, S.; Zhou, F.; Wang, L.; Zhang, J. Preparation of $\mathrm{Cu}_{2} \mathrm{O} / \mathrm{CeO}_{2}$ heterojunction photocatalyst for the degradation of Acid Orange 7 under visible light irradiation. Catal. Commun. 2011, 12, 794-797. [CrossRef]

8. Awfa, D.; Ateia, M.; Fujii, M.; Yoshimura, C. Novel magnetic carbon nanotube-TiO 2 composites for solar light photocatalytic degradation of pharmaceuticals in the presence of natural organic matter. J. Water Process Eng. 2019, 31, 100836. [CrossRef]

9. Awfa, D.; Ateia, M.; Fujii, M.; Yoshimura, C. Photocatalytic degradation of organic micropollutants: Inhibition mechanisms by different fractions of natural organic matter. Water Res. 2020, 174, 115643. [CrossRef]

10. Xiong, J.; Di, J.; Xia, J.; Zhu, W.; Li, H. Surface defect engineering in 2D nanomaterials for photocatalysis. Adv. Funct. Mater. 2018, 28, 1801983. [CrossRef]

11. Kong, L.; Wang, C.; Zheng, H.; Zhang, X.; Liu, Y. Defect-induced yellow color in Nb-doped $\mathrm{TiO}_{2}$ and its impact on visible-light photocatalysis. J. Phys. Chem. C 2015, 119, 16623-16632. [CrossRef]

12. Neppolian, B.; Bruno, A.; Bianchi, C.L.; Ashokkumar, M. Graphene oxide based Pt-TiO 2 photocatalyst: Ultrasound assisted synthesis, characterization and catalytic efficiency. Ultrason. Sonochem. 2012, 19, 9-15. [CrossRef]

13. Fotiou, T.; Triantis, T.M.; Kaloudis, T.; Hiskia, A. Evaluation of the photocatalytic activity of $\mathrm{TiO}_{2}$ based catalysts for the degradation and mineralization of cyanobacterial toxins and water off-odor compounds under UV-A, solar and visible light. Chem. Eng. J. 2015, 261, 17-26. [CrossRef]

14. Wöhrle, D.; Suvorova, O.; Gerdes, R.; Bartels, O.; Lapok, L.; Baziakina, N.; Makarov, S.; Slodek, A. Efficient oxidations and photooxidations with molecular oxygen using metal phthalocyanines as catalysts and photocatalysts. J. Porphyr. Phthalocyanines 2004, 8, 1020-1041. [CrossRef]

15. Zhang, M.; Wang, Q.; Chen, C.; Zang, L.; Ma, W.; Zhao, J. Oxygen atom transfer in the photocatalytic oxidation of alcohols by $\mathrm{TiO}_{2}$ : Oxygen isotope studies. Angew. Chem. Int. Ed. Engl. 2009, 48, 6081-6084. [CrossRef] [PubMed]

16. Ateia, M.; Alalm, M.G.; Awfa, D.; Johnson, M.S.; Yoshimura, C. Modeling the degradation and disinfection of water pollutants by photocatalysts and composites: A critical review. Sci. Total Environ. 2020, 698, 134197. [CrossRef] [PubMed]

17. Atkinson, A.J.; Apul, O.G.; Schneider, O.; Garcia-Segura, S.; Westerhoff, P. Nanobubble Technologies Offer Opportunities to Improve Water Treatment. Acc. Chem. Res. 2019, 52, 1196-1205. [CrossRef]

18. Thomson, W. LX. On the equilibrium of vapour at a curved surface of liquid. Lond. Edinb. Dublin Philos. Mag. J. Sci. 1871, 42, 448-452. [CrossRef]

19. Wang, Q.; Zhao, H.; Qi, N.; Qin, Y.; Zhang, X.; Li, Y. Generation and Stability of Size-Adjustable Bulk Nanobubbles Based on Periodic Pressure Change. Sci. Rep. 2019, 9, 1118. [CrossRef]

20. Matsuki, N.; Ishikawa, T.; Ichiba, S.; Shiba, N.; Ujike, Y.; Yamaguchi, T. Oxygen supersaturated fluid using fine micro/nanobubbles. Int. J. Nanomed. 2014, 9, 4495. [CrossRef]

21. Chu, L.-B.; Xing, X.-H.; Yu, A.-F.; Zhou, Y.-N.; Sun, X.-L.; Jurcik, B. Enhanced ozonation of simulated dyestuff wastewater by microbubbles. Chemosphere 2007, 68, 1854-1860. [CrossRef] 
22. Temesgen, T.; Bui, T.T.; Han, M.; Kim, T.-I.; Park, H. Micro and nanobubble technologies as a new horizon for water-treatment techniques: A review. Adv. Colloid Interface Sci. 2017, 246, 40-51. [CrossRef]

23. Ushikubo, F.Y.; Furukawa, T.; Nakagawa, R.; Enari, M.; Makino, Y.; Kawagoe, Y.; Shiina, T.; Oshita, S. Evidence of the existence and the stability of nano-bubbles in water. Colloids Surf. A Physicochem. Eng. Asp. 2010, 361, 31-37. [CrossRef]

24. Meegoda, J.N.; Aluthgun Hewage, S.; Batagoda, J.H. Stability of nanobubbles. Environ. Eng. Sci. 2018, 35, 1216-1227. [CrossRef]

25. Wang, L.; Ali, J.; Wang, Z.; Oladoja, N.; Cheng, R.; Zhang, C.; Mailhot, G.; Pan, G. Oxygen nanobubbles enhanced photodegradation of oxytetracycline under visible light: Synergistic effect and mechanism. Chem. Eng. J. 2020, 388, 124227. [CrossRef]

26. Fan, W.; Zhou, Z.; Wang, W.; Huo, M.; Zhang, L.; Zhu, S.; Yang, W.; Wang, X. Environmentally friendly approach for advanced treatment of municipal secondary effluent by integration of micro-nano bubbles and photocatalysis. J. Clean. Prod. 2019, 237, 117828. [CrossRef]

27. Yang, L.; Liya, E.Y.; Ray, M.B. Degradation of paracetamol in aqueous solutions by $\mathrm{TiO}_{2}$ photocatalysis. Water Res. 2008, 42, 3480-3488. [CrossRef] [PubMed]

28. Shan, R.; Lu, L.; Gu, J.; Zhang, Y.; Yuan, H.; Chen, Y.; Luo, B. Photocatalytic degradation of methyl orange by Ag/TiO $2 /$ biochar composite catalysts in aqueous solutions. Mater. Sci. Semicond. Process. 2020, 114, 105088. [CrossRef]

29. Li, P.; Takahashi, M.; Chiba, K. Enhanced free-radical generation by shrinking microbubbles using a copper catalyst. Chemosphere 2009, 77, 1157-1160. [CrossRef] [PubMed]

30. Minamikawa, K.; Takahashi, M.; Makino, T.; Tago, K.; Hayatsu, M. Irrigation with oxygen-nanobubble water can reduce methane emission and arsenic dissolution in a flooded rice paddy. Environ. Res. Lett. 2015, 10, 084012. [CrossRef]

31. Liu, S.; Oshita, S.; Kawabata, S.; Makino, Y.; Yoshimoto, T. Identification of ROS produced by nanobubbles and their positive and negative effects on vegetable seed germination. Langmuir 2016, 32, 11295-11302. [CrossRef]

32. Yasui, K.; Tuziuti, T.; Kanematsu, W. High temperature and pressure inside a dissolving oxygen nanobubble. Ultrason. Sonochem. 2019, 55, 308-312. [CrossRef] [PubMed]

33. Heu, R.; Ateia, M.; Awfa, D.; Punyapalakul, P.; Yoshimura, C. Photocatalytic Degradation of Organic Micropollutants in Water by Zr-MOF/GO Composites. J. Compos. Sci. 2020, 4, 54. [CrossRef]

34. Deng, W.; Zhao, H.; Pan, F.; Feng, X.; Jung, B.; Abdel-Wahab, A.; Batchelor, B.; Li, Y. Visible-Light-Driven Photocatalytic Degradation of Organic Water Pollutants Promoted by Sulfite Addition. Environ. Sci. Technol. 2017, 51, 13372-13379. [CrossRef] [PubMed]

35. Ziylan-Yavaş, A.; Ince, N.H. Enhanced photo-degradation of paracetamol on n-platinum-loaded $\mathrm{TiO}_{2}$ : The effect of ultrasound and $\mathrm{OH} /$ hole scavengers. Chemosphere 2016, 162, 324-332. [CrossRef]

36. Deng, X.; Li, Z.; Garcia, H. Visible Light Induced Organic Transformations Using Metal-Organic-Frameworks (MOFs). Chemistry 2017, 23, 11189-11209. [CrossRef]

37. Pelaez, M.; Falaras, P.; Likodimos, V.; O’Shea, K.; Armah, A.; Dunlop, P.S.; Byrne, J.A.; Dionysiou, D.D. Use of selected scavengers for the determination of $\mathrm{NF}^{-\mathrm{TiO}_{2}}$ reactive oxygen species during the degradation of microcystin-LR under visible light irradiation. J. Mol. Catal. A Chem. 2016, 425, 183-189. [CrossRef] [PubMed]

38. Li, W.; Li, D.; Lin, Y.; Wang, P.; Chen, W.; Fu, X.; Shao, Y. Evidence for the active species involved in the photodegradation process of methyl orange on $\mathrm{TiO}_{2}$. J. Phys. Chem. C 2012, 116, 3552-3560. [CrossRef]

39. Xue, B.; Sun, T.; Wu, J.K.; Mao, F.; Yang, W. AgI/ $\mathrm{TiO}_{2}$ nanocomposites: Ultrasound-assisted preparation, visible-light induced photocatalytic degradation of methyl orange and antibacterial activity. Ultrason. Sonochem. 2015, 22, 1-6. [CrossRef]

40. Lu, L.; Shan, R.; Shi, Y.; Wang, S.; Yuan, H. A novel $\mathrm{TiO}_{2}$ /biochar composite catalysts for photocatalytic degradation of methyl orange. Chemosphere 2019, 222, 391-398. [CrossRef]

41. Yao, X.; Zhang, B.; Cui, S.; Yang, S.; Tang, X. Fabrication of $\mathrm{SnSO}_{4}$-modified $\mathrm{TiO}_{2}$ for enhance degradation performance of methyl orange (MO) and antibacterial activity. Appl. Surf. Sci. 2021, 149419. [CrossRef]

42. Mahalakshmi, G.; Rajeswari, M.; Ponnarasi, P. Synthesis of few-layer g-C3N4 nanosheets-coated $\mathrm{MoS}_{2} / \mathrm{TiO}_{2}$ heterojunction photocatalysts for photo-degradation of methyl orange (MO) and 4-nitrophenol (4-NP) pollutants. Inorg. Chem. Commun. 2020, 120, 108146. [CrossRef]

43. Barka, N.; Assabbane, A.; Nounah, A.; Dussaud, J.; Ichou, Y.A.J.P.C.N. Photocatalytic degradation of methyl orange with immobilized $\mathrm{TiO}_{2}$ nanoparticles: Effect of $\mathrm{pH}$ and some inorganic anions. Phys. Chem. News 2008, 41, 85-88.

44. Grover, I.S.; Singh, S.; Pal, B. The preparation, surface structure, zeta potential, surface charge density and photocatalytic activity of $\mathrm{TiO}_{2}$ nanostructures of different shapes. Appl. Surf. Sci. 2013, 280, 366-372. [CrossRef]

45. Harnung, S.E.; Johnson, M.S. Chemistry and the Environment; Cambridge University Press: Cambridge, MA, USA, 2012.

46. Bouanimba, N.; Laid, N.; Zouaghi, R.; Sehili, T. Effect of $\mathrm{pH}$ and inorganic salts on the photocatalytic decolorization of methyl orange in the presence of $\mathrm{TiO}_{2}$ P25 and PC500. Desalination Water Treat. 2015, 53, 951-963.

47. Nirmalkar, N.; Pacek, A.W.; Barigou, M. On the Existence and Stability of Bulk Nanobubbles. Langmuir 2018, 34, 10964-10973. [CrossRef] [PubMed]

48. Agarwal, A.; Ng, W.J.; Liu, Y. Principle and applications of microbubble and nanobubble technology for water treatment. Chemosphere 2011, 84, 1175-1180. [CrossRef]

49. Niu, P.; Hao, J. Fabrication of Titanium Dioxide and Tungstophosphate Nanocomposite Films and Their Photocatalytic Degradation for Methyl Orange. Langmuir 2011, 27, 13590-13597. [CrossRef] 
50. Bahrudin, N.N.; Nawi, M.A.; Zainal, Z. Insight into the synergistic photocatalytic-adsorptive removal of methyl orange dye using $\mathrm{TiO}_{2}$ /chitosan based photocatalyst. Int. J. Biol. Macromol. 2020, 165, 2462-2474. [CrossRef]

51. Gomathi Devi, L.; Mohan Reddy, K. Enhanced photocatalytic activity of silver metallized $\mathrm{TiO}_{2}$ particles in the degradation of an azo dye methyl orange: Characterization and activity at different $\mathrm{pH}$ values. Appl. Surf. Sci. 2010, 256, 3116-3121. [CrossRef]

52. Azevedo, A.; Etchepare, R.; Calgaroto, S.; Rubio, J. Aqueous dispersions of nanobubbles: Generation, properties and features. Miner. Eng. 2016, 94, 29-37. [CrossRef] 